\title{
Efeitos da variação da concentração de solução polimérica aquosa a base de PVP na têmpera de aço AISI 4140
}

\author{
Effects of the variation of the concentration \\ of aqueous polymer solution based on PVP \\ in the quenching of AISI 4140 steel
}

Eduardo da Rosa Vieira ${ }^{1}$, Luciano Volcanoglo Biehl1, Jorge Luis Braz Medeiros ${ }^{1}$,Alex Britto da Silva ${ }^{1}$, Marcos Saalfeld da Silva ${ }^{1}$

\footnotetext{
${ }^{1}$ Programa de Pós-Graduação em Engenharia Mecânica - Universidade Federal do Rio Grande - FURG, Campus Carreiros, Av. Itália, Km 8, s/n - CEP: 96203-900, Carreiros, Rio Grande do Sul, Brasil.

e-mail: vieira.r.eduardo@hotmail.com, lucianobiehl@furg.br, jorge.braz@furg.br, alexbrittodasilva@gmail.com, marcosaalfeld@gmail.com
}

\begin{abstract}
RESUMO
A têmpera é um tratamento térmico que tem como principal objetivo a elevação de dureza e resistência mecânica dos aços por meio da sua transformação microestrutural. O processo se baseia na elevação da temperatura do material até a austenitização, seguida do arrefecimento por meio da imersão em um fluido, a qual precisa ser rápida o suficiente para evitar a difusão do carbono, visando a formação de uma microestrutura predominantemente martensítica. Atualmente, vem sendo utilizado para esse procedimento as soluções poliméricas aquosas, que são misturas de água com polímeros. A concentração das soluções é um fator fundamental para a capacidade de troca de calor dos fluidos e, por consequência, a variação desse fator promove o desenvolvimento de diferentes propriedades mecânicas no material temperado. Assim, o presente trabalho consistiu na avaliação das propriedades do aço AISI 4140 temperado em soluções poliméricas aquosas a base de polivinilpirolidona (PVP) sob as concentrações de 10, 15, 20 e 25\%. Para isso, a caracterização do aço foi realizada por meio da avaliação microestrutural, microdureza e difração de raios-x. Por meio dessas avaliações, foi demonstrado que a capacidade de retirada de calor do material vai sendo minimizada de acordo com a adição de PVP à solução. Assim, a diminuição de troca térmica determinou menor formação de martensita e decréscimo no perfil de microdureza das amostras, embora não tenha sido evidenciada variação de fases em todas as situações de processo.
\end{abstract}

Palavras-chave: Têmpera, AISI 4140, Soluções Poliméricas Aquosas, PVP.

\begin{abstract}
Quenching is a heat treatment whose main objective is to increase the hardness and mechanical strength of the steels by their microstructural transformation. The process is based on increasing the temperature of the material to austenitization, followed by cooling by immersion in a fluid, which needs to be fast enough to avoid diffusion of the carbon, aiming at the formation of a predominantly martensitic microstructure. Aqueous polymer solutions, which are blends of water with polymer, have been used now for this procedure. The concentration of these solutions is a fundamental factor for the heat exchange capacity of the fluids and, consequently, the variation of this factor promotes the development of different mechanical properties in the quenched material. Thus, the present work consisted in the evaluation of the properties of quenched AISI 4140 steel in aqueous polymer solutions based on polyvinylpyrrolidone (PVP) at concentrations of 10, 15, 20 and $25 \%$. For this, the characterization of the steel was made by the microstructural evaluation, microhardness and X-ray diffraction. Through these evaluations, it has been demonstrated that the heat withdrawal capacity of the material is being minimized according to the addition of PVP to the solution. As a result, the decrease in the thermal exchange determined a lower martensite formation and a decrease in the microhard-
\end{abstract}


ness profile of the samples, although no phase variation was observed in all the process situations.

Keywords: Quenching, AISI 4140, Aqueous Polymer Solutions, PVP.

\section{INTRODUÇÃO}

A têmpera é um tratamento térmico que busca o aumento da dureza e resistência mecânica do material por meio da transformação microestrutural. Na maioria dos casos, a microestrutura alvo é a martensita, a qual é obtida por um processo sem difusão de carbono [1]. Para a execução do tratamento de têmpera é necessário que a peça esteja em uma temperatura elevada o suficiente para provocar sua austenitização, seguido da imersão rápida em um fluido de arrefecimento. Ao entrar em contato com o fluido, o corpo aquecido desenvolve três estágios consecutivos: filme de vapor, ebulição e convecção [2,3].

O primeiro estágio, filme de vapor, é caracterizado pela formação de uma cápsula de vapor ao redor da peça. Dessa maneira, fica impedida a troca de calor por condução e convecção, minimizando severamente a capacidade de resfriamento do material. Em geral, o colapso desse filme inicia na extremidade inferior da peça e vai progredindo até a superfície superior. Essa quebra progressiva da camada de vapor provoca um gradiente de taxas de troca térmica ao longo do material, resultando em variações das propriedades mecânicas ao longo do corpo [4].

Quando ocorre a transformação microestrutural da austenita para martensita é desenvolvido um aumento de volume da rede cristalina entre 2 e $4 \%$ [5]. Essa variação volumétrica provoca elevação das tensões residuais do material, em função das expansões e compressões desenvolvidas durante o processo. Além disso, o resfriamento não uniforme da peça, desencadeado pelo colapso gradual da camada de vapor, provoca uma expansão não uniforme, elevando a magnitude das tensões residuais provenientes do tratamento. $\mathrm{O}$ aumento demasiado dessas tensões pode atingir o limite de escoamento e o de ruptura do material, provocando a eclosão de distorções e trincas [4,6].

As soluções poliméricas aquosas são fluidos à base de água contendo polímeros dissolvidos. A utilização desses fluidos para arrefecimento no processo de têmpera apresenta diversas vantagens em relação aos fluidos tradicionais empregados nesse processo, como o óleo mineral, a água e as salmouras. Os benefícios mais evidentes das soluções poliméricas são a biodegradabilidade, os baixos índices de inflamabilidade, baixa toxicidade e a flexibilidade do processo [7]. Além disso, um fator diferencial dessas soluções é o mecanismo de troca de calor desenvolvido durante o processo. Ao contrário dos fluidos de têmpera tradicionais, as soluções poliméricas apresentam um colapso instantâneo do filme de vapor em toda a peça, não desenvolvendo um gradiente de troca térmica. Dessa forma, são desenvolvidas propriedades mais uniformes ao longo do corpo e as tensões residuais são reduzidas [8].

A concentração das soluções configura o principal parâmetro de flexibilização do processo, visto que influenciam diretamente a capacidade de troca térmica dos fluidos. De maneira geral, a elevação da quantidade de polímero eleva a viscosidade da solução, diminuindo a velocidade do resfriamento, e, por consequência, reduzindo a capacidade de formação de martensita. Isso ocorre porque conforme eleva-se a concentração, a camada de vapor formada torna-se mais espessa, dificultando seu colapso. Em função disso, o tempo de duração do primeiro estágio do processo é prolongado, resultando em um resfriamento mais lento do corpo em virtude da baixa troca térmica, que ocorre de forma exclusiva por radiação [9].

Em estudos realizados com o polímero de têmpera polialquilenoglicol (PAG), o qual representa um dos polímeros mais difundidos para o arrefecimento de materiais, fica evidente que o aumento progressivo do polímero à solução minimiza gradualmente a capacidade de retirada de calor das peças. Nesse experimento, foi realizada a têmpera de amostras de AISI 1080, em água e em soluções com as concentrações de 5, 10, 25, 50,75 e $100 \%$ de PAG. Assim sendo, verificou-se que em 5\% há as mais elevadas taxas de troca térmica, as quais são próximas às taxas da água, seguidas de 10 e $25 \%$ de PAG. A partir de $50 \%$ o arrefecimento das amostras começa a ser mais lento, dificultando a transformação adifusional da microestrutura. Isso fica mais evidente quando constatado que as amostras temperadas em água, 5 e $10 \%$ de PAG obtiveram 93\% de martensita em sua composição, enquanto que as resfriadas em 25 e $50 \%$ apresentaram uma queda para, respectivamente, 90 e $82 \%$ de martensita. Quando o material foi arrefecido em $75 \%$ de PAG apresentou $31 \%$ de martensita e o arrefecido em 100\% de PAG obteve apenas 0,6\% desse microconstituinte, evidenciando o insucesso do procedimento [9].

Por sua vez, o polivinilpirolidona (PVP) é um polímero com alta solubilidade em água e que também possui capacidade de arrefecimento variável, de acordo com seu percentual de diluição [7]. Em comparação com outros fluidos de têmpera, o PVP apresenta uma fase de filme de vapor mais curta, ao passo que seus estágios de ebulição e convecção são prorrogados. Isso ocorre porque o PVP não evapora totalmente com a 
água, permanecendo adjacente à superfície da peça, possibilitando a formação de uma camada de vapor instável e susceptível â quebra $[9,10]$. Em comparação com o PAG, o PVP apresenta maior capacidade de arrefecimento e sob as mesmas condições de concentração e temperatura de banho, o PVP pode desenvolver uma taxa de resfriamento até 38,6\% maior quando, os fluidos são arrefecidos a uma velocidade de agitação igual a $0,75 \mathrm{~m} / \mathrm{s}$, e 51,5\% quando não há agitação. [11]. Assim como outros fluidos poliméricos, a viscosidade do PVP aumenta com a concentração. Koudil, Z. et al [7] avaliou a viscosidade cinemática de soluções poliméricas a base de PVP, na qual as concentrações de 5, 10, 15 e 20\% apresentaram, respectivamente, índices aproximados de 2, 6, 11, e 20 cSt. [7]

Segundo os estudos de Grum, J. et al [6], a têmpera de barras cilíndricas de aço AISI 4140, com $35 \mathrm{~mm}$ de diâmetro e $5 \mathrm{~mm}$ de altura, utilizando de uma solução a base de PVP com 10\% de concentração como fluido de arrefecimento, desenvolveu um perfil de microdureza variando entre 840 e $700 \mathrm{HV}$. Os índices mais elevados foram desenvolvidos próximo à superfície da peça enquanto que os menores foram localizados no centro. Comparativamente, os estudos de Totic, Y. [12], demonstraram que esse mesmo aço quando temperado em água e em óleo desenvolveu valores próximos a 760 HV para a água e $590 \mathrm{HV}$ para o óleo, ambos medidos na sua superfície da peça [12]. Outros experimentos, evidenciaram que o material quando submetido à têmpera em água apresentou $60 \mathrm{HRC}$ em sua superfície e $55 \mathrm{HRC}$ ao ser resfriado em óleo, valores referentes, respectivamente, a 700 e $595 \mathrm{HV}[13,14,15]$.

Em geral, os tratamentos térmicos de têmpera desse material desenvolvem como resultado a martensita, podendo também desenvolver bainita e, eventualmente, uma pequena quantidade de austenita retida. A microestrutura resultante depende das condições de processo, as quais influenciam diretamente na velocidade de resfriamento [1]. Além da observação microestrutural, os componentes do material podem ser averiguados por meio da difração de raios-x, a qual possibilita a identificação dos índices de Miller dos planos cristalinos do aço $[16,17]$.

Em razão das variadas aplicações do aço AISI 4140 associada à crescente expansão do uso de polímeros para a têmpera de metais, é necessário conhecer seus efeitos no material em estudo, visto as vantagens que esse fluido pode agregar ao processo. Nesse sentido, o presente trabalho tem como intuito avaliar os efeitos da têmpera do aço utilizando diversas concentrações de soluções poliméricas aquosas a base de PVP. Os efeitos da alteração da capacidade de resfriamento decorrente da adição de soluto à solução serão evidenciados por meio da avaliação da quantidade martensítica resultante, da variação da sua microdureza e da investigação dos índices de Miller presentes no material após o tratamento térmico.

\section{MATERIAIS E MÉTODOS}

Para a realização do estudo, foram utilizadas amostras de aço AISI/SAE Gerdau 4140. As amostras do aço selecionadas para o tratamento possuíam geometria cilíndrica, com $10 \mathrm{~mm}$ de altura e $25,4 \mathrm{~mm}$ de diâmetro. Para cada situação de têmpera realizada no trabalho foram utilizadas três amostras, garantindo uma prova e uma contraprova dos resultados. As amostras foram nomeadas como "10A", "10B", "10C", "15A", "15B", "15C", "20A", "20B", "20C", "25A", "25B" e "25C", onde os dois primeiros algarismos representam a concentração da solução na qual foram arrefecidas.

As soluções poliméricas a base de PVP foram preparadas a partir do polímero base Durquench 90, da marca Durferrit. Para a utilização no estudo, foram preparados $5000 \mathrm{~cm}^{3}$ de cada uma das soluções, as quais apresentavam concentrações de $10,15,20$ e $25 \%$.

É importante salientar que, antes do procedimento de têmpera, visando averiguar as propriedades físico-químicas dos materiais, foram caracterizadas as amostras de aço e dos fluidos de arrefecimento. Os aços foram expostos à espectrometria óptica, com o intuito de assegurar que sua composição química estava dentro dos limites aceitáveis para o material. Esse processo foi realizado utilizando um espectrômetro de emissão óptica modelo Foundry-Master Pro, marca Hitachi. Por sua vez, os fluidos de têmpera foram ensaiados com o intuito de averiguar sua viscosidade cinemática, a qual interfere diretamente na capacidade de troca térmica [9]. Esse procedimento foi realizado por meio de um viscosímetro capilar marca Cannon-Fensk, modelo GMBH-D65719. Para a amostra com 10\% de PVP foi utilizado um capilar número 75, já para as demais amostras o capilar utilizado foi o número 100. As viscosidades cinemáticas, em centistokes $\left(\mathrm{mm}^{2} / \mathrm{s}\right)$, foram calculadas segundo a equação:

$$
v=K \cdot \Delta t
$$

Onde $v$ representa a viscosidade cinemática, $\mathrm{K}$ a constante do capilar em $\mathrm{mm}^{2} / \mathrm{s}$ e $\Delta t$ a variação do 
tempo de escoamento em segundos.

$\mathrm{O}$ procedimento de têmpera se baseou no aquecimento das amostras até a temperatura de $880^{\circ} \mathrm{C}$ [1] durante 60 minutos em um forno resistivo tipo mufla, marca EDG, modelo 3000. Em seguida, foram imersas nos fluidos de arrefecimento a temperatura ambiente, aproximadamente $25^{\circ} \mathrm{C}$. O volume de cada fluido utilizado foi de $5000 \mathrm{~cm}^{3}$ e estavam contidos em um tanque construído de material acrílico, com capacidade aproximada de $9000 \mathrm{~cm}^{3}$. Esse tanque era agitado por uma bomba de recirculação que desenvolvia no seu recalque $0,7 \mathrm{~m} / \mathrm{s}$. Após a têmpera, os corpos de prova foram novamente levados ao forno para que fossem revenidos a $180^{\circ} \mathrm{C}$ durante 60 minutos.

Para avaliação dos resultados, as amostras foram seccionadas transversalmente, com o intuito de observar a microdureza e a microestrutura de cada amostra. A microdureza do material foi avaliada por um microdurômetro Vickers Shimadzu, modelo HMV 2T, utilizando identação com 0,3 N de força durante 10 segundos. Para a construção do perfil de microdureza foram selecionados 8 pontos entre a superfície e o núcleo no sentido radial da peça. A Tabela 1 demonstra as posições dos pontos avaliados na microdureza. O ponto 1 é mais próximo da superfície da amostra, enquanto o ponto 8 está localizado no centro.

Tabela 1: Pontos de microdureza

\begin{tabular}{ccccccccc}
\hline \multicolumn{10}{c}{ Pontos de Microdureza } \\
\hline \hline Pontos & 1 & 2 & 3 & 4 & 5 & 6 & 7 & 8 \\
\hline Distância $(\mathrm{mm})$ & 0,1 & 1,9 & 3,7 & 5,5 & 7,3 & 9,1 & 10,9 & 12,7 \\
\hline
\end{tabular}

A microscopia óptica foi utilizada para observar a microestrutura das peças e possibilitar o cálculo da quantidade de fases presentes no material, nesse procedimento foi empregado um microscópio óptico de luz refletida marca Olympus, modelo GX 51S. O aumento foi de 500 vezes e para cada uma das amostras foram obtidas imagens do centro e de uma região próxima à superfície. A quantificação das fases foi realizada por meio do software livre de análise de imagens ImageJ, o qual faz a diferenciação das fases por cores e calcula o total das suas áreas, possibilitando a interpretação do percentual aproximado das fases presentes.

A difração de raios-x, utilizada com a intenção de realizar uma caracterização complementar das amostras, foi realizada em um difratômetro de raios-x da marca Bruker, modelo G8 Advance. A ideia desse procedimento foi reconhecer os índices de Miller do material, possibilitando a identificação das fases presentes no material após o tratamento. A aquisição do espectro ocorreu entre 20 e $90^{\circ}$, utilizando um ânodo de cobre, com comprimento de onda igual a $0,15406 \mathrm{~nm}$ e passo de $0,02^{\circ}$. A interpretação do espectro, identificação dos picos e reconhecimento dos índices de Miller foram efetivados por intermédio do software Diffrac EVA.

\section{RESULTADOS E DISCUSSÃO}

Após a execução da espectrometria, foram demonstradas as quantidades de elementos de liga e elementos residuais contidas no material, conforme a Tabela 2.

Tabela 2: Composição química do aço AISI 4140

\begin{tabular}{cccccccc}
\hline \multicolumn{7}{c}{ AISI 4140 } \\
\hline \hline Elemento & Carbono & Cromo & Molibdênio & Manganês & Silício & Fósforo & Enxofre \\
\hline Limites (\%) & $0,38-0,45$ & $0,80-1,10$ & $0,15-0,25$ & $0,75-1,00$ & $0,20-0,35$ & 0,0035 máx & 0,0040 máx \\
Medido (\%) & 0,443 & 0,991 & 0,163 & 0,963 & 0,342 & 0,003 & 0,003 \\
\hline
\end{tabular}

Diante dos resultados, observou-se que a quantidade de elementos de liga e residuais do aço AISI 4140 está dentro dos índices estabelecidos [18], assim, determina-se que o material atende às expectativas de temperabilidade.

A partir da medição dos tempos de escoamentos dos fluidos, foram calculadas suas viscosidades cinemáticas, apresentadas na Tabela 3. 
Tabela 3: Caracterização dos fluidos de têmpera

\begin{tabular}{ccccc}
\hline \multicolumn{5}{c}{ Fluidos de Têmpera } \\
\hline \hline Fluido & Tempo $(\mathrm{s})$ & Capilar $\left(\mathrm{N}^{\circ}\right)$ & $\mathrm{K}\left(\mathrm{mm}^{2} / \mathrm{s}^{2}\right)$ & Visc. Cinemática (cSt) \\
\hline $10 \%$ PVP & 371 & 75 & 0,008 & 2,97 \\
$15 \%$ PVP & 331 & 100 & 0,015 & 4,96 \\
$20 \%$ PVP & 454 & 100 & 0,015 & 6,81 \\
$25 \%$ PVP & 664 & 100 & 0,015 & 9,96 \\
\hline
\end{tabular}

A partir dos resultados, podemos observar um crescimento dos índices de acordo com a adição de soluto. Dessa forma, as viscosidades cinemáticas obtiveram aumentos significativos com a elevação da concentração [19]. No entanto, embora apresente uma tendência de crescimento de viscosidade semelhante, os índices medidos são consideravelmente menores do que os apresentados nos estudos de Koudil, Z. et al [7]. Vale ressaltar que, apesar de se tratar do mesmo polímero, a origem do produto não é a mesma. Ainda, foi demonstrado que fluidos de têmpera poliméricos de diferentes fabricantes desenvolvem capacidades distintas de arrefecimento. Além disso, as medições foram realizadas antes de utilizações prévias das soluções. É provável que após alguns ciclos de tratamentos térmicos ocorra uma degradação das soluções, reduzindo progressivamente as viscosidades e elevando a capacidade refrigerante [20]. Vale lembrar que o crescimento dos índices de viscosidade diminui a capacidade de arrefecimento dos fluidos, minimizando a retirada de calor das peças e, por consequência, dificultando a transformação martensítica [19].

Em função da variação do mecanismo da troca de calor entre a superfície, que entra em contato com o fluido, e o núcleo, que troca calor apenas por condução, é esperado que exista variação da formação de fases entre esses pontos do material [1]. Dessa forma, com o intuito de confrontar os diferentes resultados, foram obtidas imagens da superfície (Figura 1) e do núcleo do material (Figura 2). 


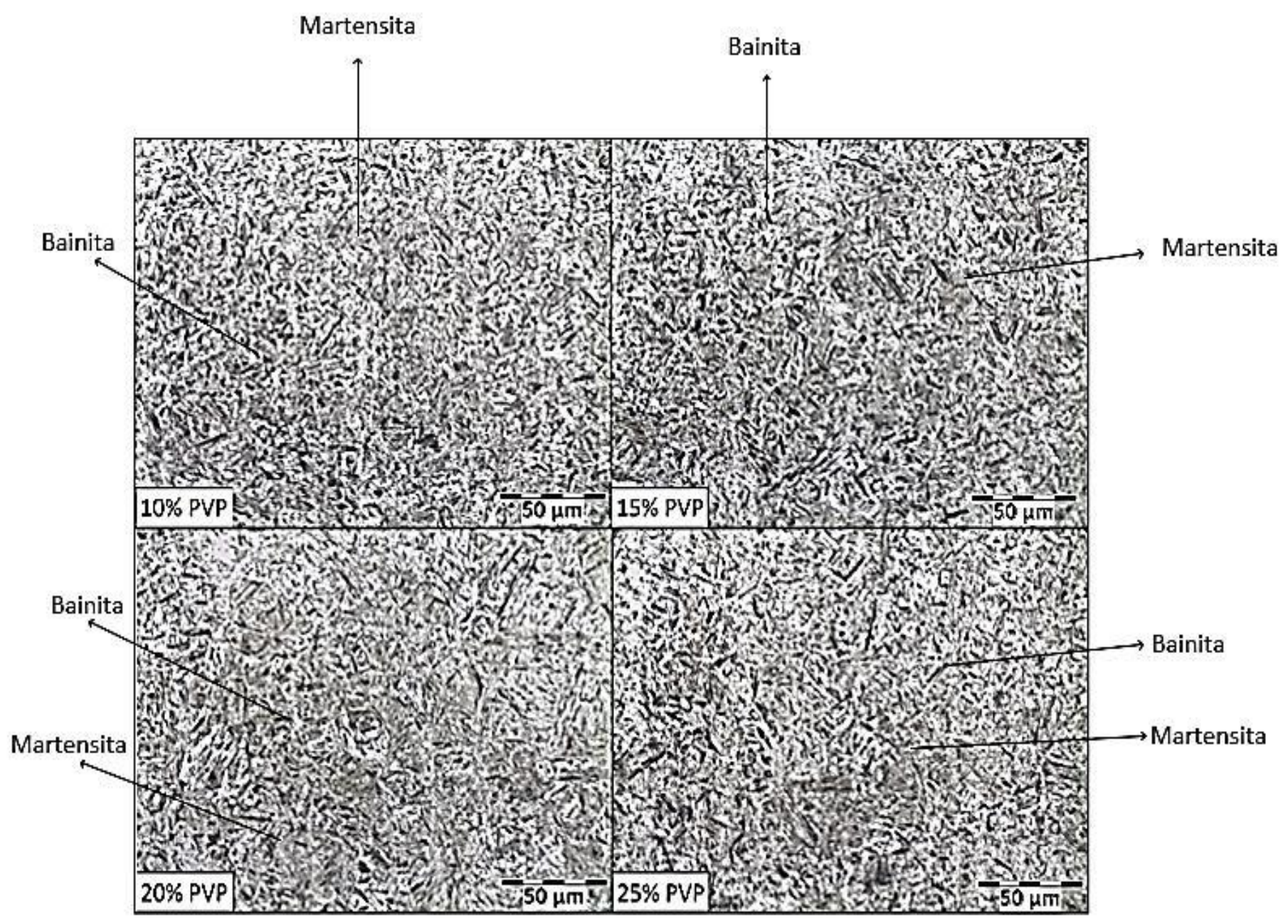

Figura 1: Microestrutura formada na superfície do material de acordo com a concentração de PVP na qual foi arrefecida 


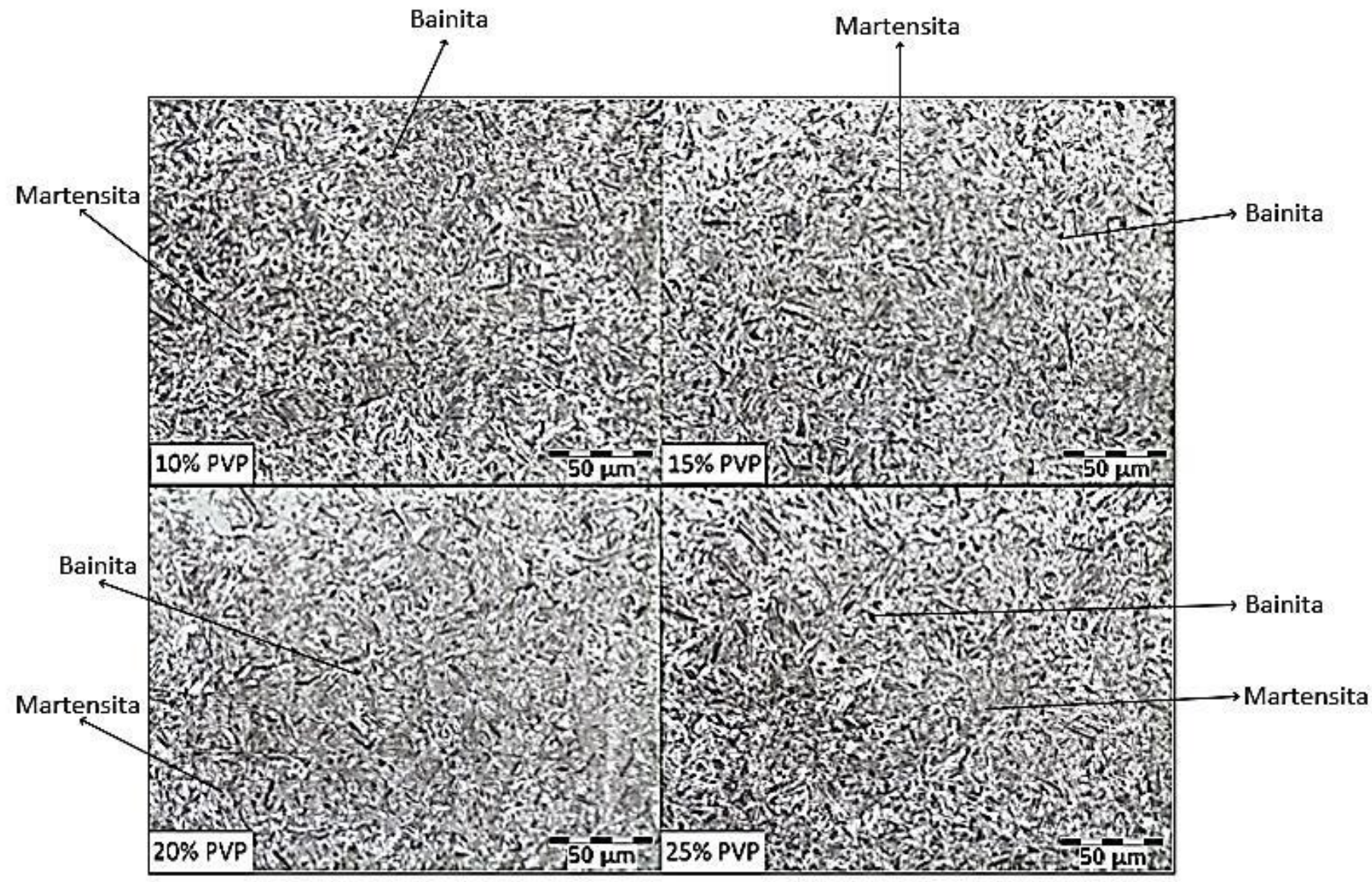

Figura 2: Microestrutura formada no centro do material de acordo com a concentração de PVP na qual foi arrefecida

Em todas as situações do processo observou-se a existência de uma formação predominante de martensita, e em todos dos casos, existe bainita dispersa na matriz martensítica. Visando averiguar a quantidade aproximada de fases presentes no aço tratado em cada fluido de têmpera, as imagens foram expostas à técnica de diferenciação de fases por cores, utilizando o software ImageJ e as quantificações encontram-se a seguir na Tabela 4 [21].

Tabela 4: Quantificação das fases

\begin{tabular}{lccc}
\hline \multicolumn{4}{c}{ AISI 4140} \\
\hline \hline \multirow{2}{*}{$10 \%$ PVP } & Martensita (\%) & Bainita (\%) \\
& Nuperfície & 98,7 & 1,3 \\
& Núcleo & 92,8 & 7,2 \\
\hline \multirow{2}{*}{$15 \%$ PVP } & Superfície & 92,3 & 7,7 \\
& Núcleo & 81,5 & 18,5 \\
\hline \multirow{2}{*}{$20 \%$ PVP } & Superfície & 92,1 & 7,9 \\
& Núcleo & 79,1 & 20,9 \\
\hline \multirow{2}{*}{$25 \%$ PVP } & Superfície & 90,8 & 9,2 \\
& Núcleo & 67,5 & 32,5 \\
\hline
\end{tabular}


A partir dos resultados obtidos, observou-se a elevação de índice de bainita em função do aumento da concentração da solução. Além disso, constatou-se variação entre superfície e núcleo. As camadas mais externas resfriam primeiro, apresentando índices mais elevados de martensita, com formação bainítica entre 1,3 e 9,2\%. Já as camadas internas formam maior quantidade de bainita, com porcentagem entre 7,2 e 32,5\%. É importante ressaltar que para todas as soluções não foi observada formação de ferrita e perlita, o que demonstra o sucesso do tratamento de têmpera, previamente evidenciado pela matriz martensítica $[1,18]$.

Os perfis de microdureza do material (Figura 3) foram construídos por meio das medições entre a superfície e o núcleo, e as identações foram executadas a cada $1,8 \mathrm{~mm}$.

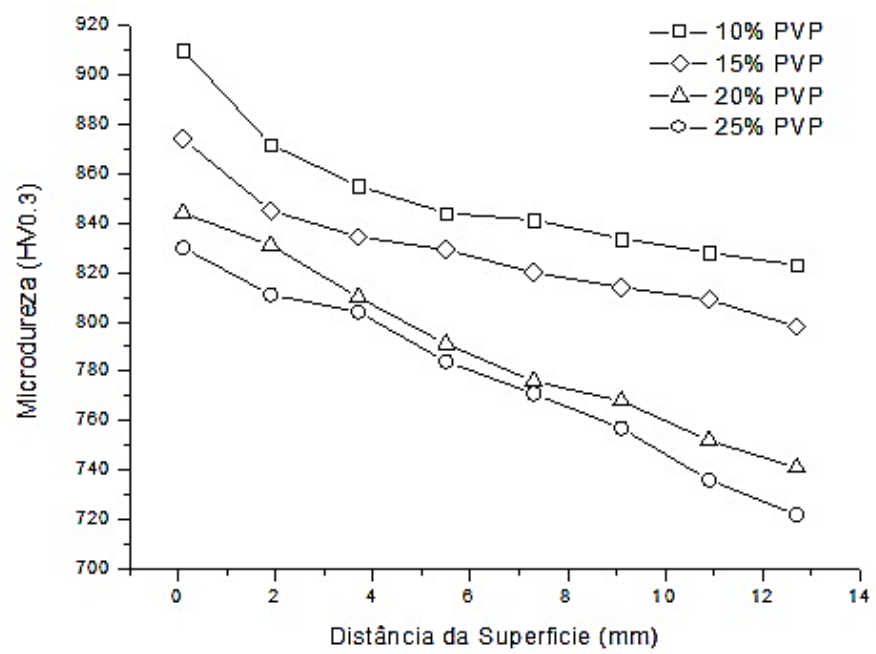

Figura 3: Perfis de microdureza do material arrefecido nas diferentes concentrações de PVP

Os perfis de microdureza do aço demonstram uma diminuição da microdureza a partir da superfície até o centro do corpo, apresentando diferenças entre 108 e 76 HV0.3. Esses índices são decrescentes de acordo com o aumento das concentrações de polímero, em função da diminuição da taxa de arrefecimento [22]. Assim, percebemos que o padrão de microdureza da solução com $10 \%$ de concentração possui os patamares mais elevados e a concentração de $25 \%$ têm os índices mais baixos [9]. Além disso, é importante salientar que os índices de microdureza apresentam coerência com os resultados prévios tanto da caracterização dos fluidos de têmpera quanto da microestrutura do material. Assim, verifica-se que a elevação da concentração do polímero na solução desencadeia a redução quantidade de microdureza, a qual ocorre em função da minimização da quantidade de martensita e elevação da bainita [1]. Em comparação com os resultados de Grum, J.. et al [6], o qual mediu o perfil de microdureza de aço AISI 4140 arrefecido em 10\% de PVP, os índices de microdureza resultados obtidos foram mais elevados. Entretanto, o comportamento do perfil de microdureza desenvolvido foi muito semelhante, demonstrando uma mesma tendência de queda a partir da superfície até o núcleo [6].

Por meio do software Diffrac EVA foram gerados os espectros e identificados seus picos e índices de Miller, conforme Figura 4.

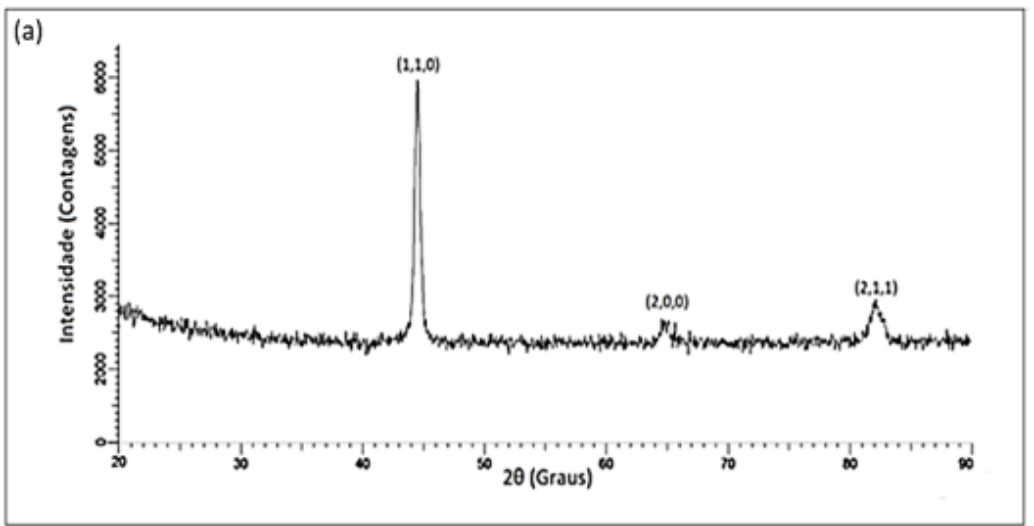



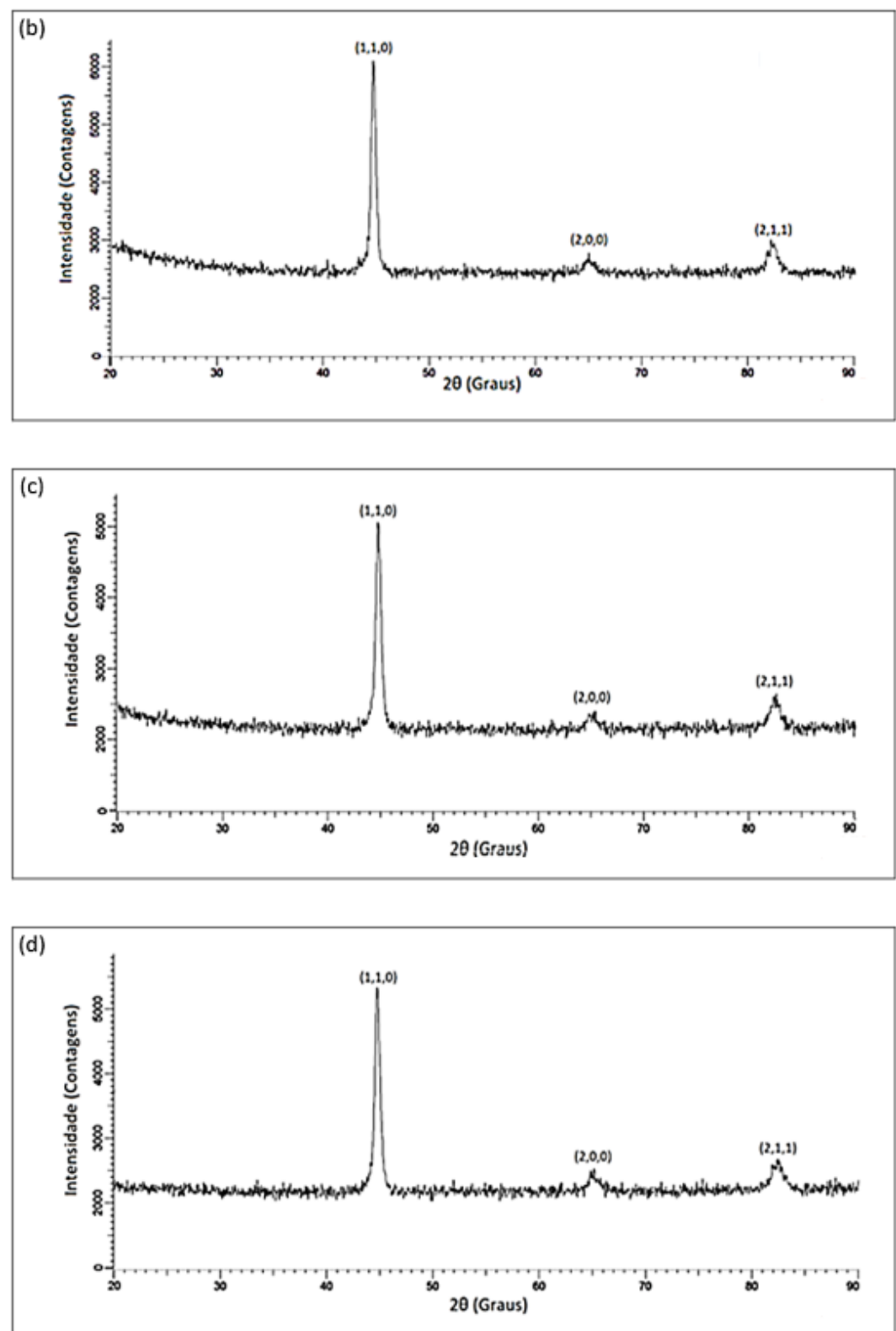

Figura 4: Espectros difratométricos dos aços AISI 4140 temperados em PVP sob concentrações de 10\% (a), 15\% (b), $20 \%$ (c) e $25 \%$ (d)

A partir dos espectros observou-se um mesmo padrão entre todos os meios refrigerantes, os quais demonstram a existência de três picos bem definidos, diferenciando-se apenas pela intensidade. Os índices de Miller encontrados foram os mesmos para todos os fluidos, e eles se referem à para ferrita e martensita [16]. Os dois picos de maior intensidade, representados pelos índices $(1,1,0)$ e $(2,1,1)$, localizados respectivamente em $2 \theta=44,4^{\circ}$ e $2 \theta=82^{\circ}$, são referentes à martensita. Por sua vez, o pico menor, indicado por $(2,0,0)$, é relativo ao ferro alfa, presente na bainita [17]. Os índices de Miller do ferro gama, componente da austenita retida, são $(1,1,1),(2,0,0),(2,2,0),(3,1,1)$ e seus múltiplos. Enquanto $(1,1,1),(2,2,0)$ e $(3,1,1)$ não foram encontrados no espectro, o índice $(2,0,0)$ presente nas amostras se refere à ferrita, visto que foi encontrado em $2 \theta=$ $64,7^{\circ}$ e os índices $(2,0,0)$ referentes à austenita se encontram entre $2 \theta \approx 51^{\circ}$. [17,23].

A análise dos índices de Miller provenientes dos difratogramas demonstram que não foi encontrado o ferro gama no material tratado termicamente, comprovando a inexistência de austenita retida [17]. É importante salientar que os resultados obtidos por meio da difração de raio-x são coerentes com o histórico de análises microscópicas do material. Assim, observa-se que não existe nenhuma variação dos tipos de fases existentes após os tratamentos em diferentes concentrações, as quais variam apenas a quantidade presente no aço [16]. 


\section{CONCLUSÕES}

A adição de PVP às soluções eleva a viscosidade cinemática do fluido, reduzindo a capacidade de arrefecimento, minimizando a formação martensítica e os índices de microdureza.

As concentrações das soluções poliméricas aquosas a base de PVP entre 10 e $25 \%$ permitem a formação de microestrutura predominantemente martensítica para o aço AISI 4140.

A observação da quantificação de fases do material permite concluir que existe uma diferença de formação martensítica entre núcleo e superfície das amostras e que os a quantidade de martensita diminui conforme a concentração é elevada.

A análise dos perfis de microdureza das amostras temperadas permite observar que existe uma queda de até 108HV0.3 de microdureza no sentido do núcleo da peça. Além disso, o aumento da concentração minimiza os índices de microdureza.

Por meio dos índices de Miller é comprovado a existência das mesmas fases para todas as concentrações de PVP as quais o aço foi arrefecido.

\section{BIBLIOGRAFIA}

[1] TOTTEN, G.E., "Steel heat treatment handbook", 2 ed., New York, CRC Press, 2007.

[2] BUCZEK, A., TELEJKO, T., "Investigation of heat transfer coefficient during quenching in various cooling agents", International Journal of Heat and Fluid Flow, v. 44, pp. 358-364, Dec. 2013.

[3] HEMING, C., XIEQING, H., JIANBIN, X., "Comparison of surface heat-transfer coefficients between various diameter cylinders during rapid cooling", Journal of Materials Processing Technology, v. 138, pp. 399-402, Jul. 2003.

[4] HERNANDEZ, H.J.V., MORALES, B.H., "A novel probe design to study wetting front kinematics during forced convective quenching", Experimental Thermal and Fluid Science, v. 33, pp. 797-807, Jul. 2009.

[5] MAGEE, C.L., DAVIES, R.G., "The volume expansion accompanying the F.C.C. to B.C.C. transformation in ferrous alloys", Acta Metallurgica, v. 20, pp. 1031-1043, Aug. 1972.

[6] GRUM, J., BOZIC, S., "Influence of steel masses and quenchants on mechanical properties of steel", International Journal of Materials and Product Technology, v. 24, pp. 224-240, Oct. 2005.

[7] KOUDIL, Z., IKKENE, R., MOUZALI, M., "Cooling capacity optimization: calculation of hardening power of aqueous solution based on poly(n-vinyl-2-pyrrolidone)", Journal of Materials Engineering and Performance, v. 23, pp. 551-559, Dec. 2014.

[8] IKKENE, R., KOUDIL, Z., MOUZALI, M. "Cooling characteristic of polymeric quenchant: calculation of HTC and prediction of microstructure and hardness", Journal of Materials Engineering and Performance, v. 23, pp. 3819-3830, Nov. 2014.

[9] RAMESH, G., PRABHU, K.N., "Effect of polymer concentration on wetting and cooling performance during immersion quenching", Metallurgical and Materials Transactions B, v. 47, pp. 859-881, Dec. 2016.

[10] SARKAR, I., et al., "Effect of polymer additive on the cooling rate of a hot steel plate by using water jet", Experimental Thermal and Fluid Science, v. 70, pp. 105-114, Jan. 2016.

[11] HILDER, N.A. Polymer Quenchants: A Review. Heat Treatments Methods, v. 13, pp. 15-26, 1986.

[12] TOTIC, Y. "The corrosion behaviour of manganese phosphate coatings applied to AISI 4140 steel subjected to different heat treatments", Surface and Coatings Technology, v. 200, pp. 2711-2717, Nov. 2004.

[13] MEYSAMI, A.H., GHASEMZADEH, R., SEYEDEIN, S.H., et al., "An investigation on the microstructure and mechanichal properties of direct-quenched and tempered AISI 4140 steel", Materials and Design, v. 31, pp. 1570-1575, Sep. 2009.

[14] SENTHILKUMAR, D., RAJENDRAN, I., "Effect of cryogenic treatment on the hardness and tensile behavior of AISI 4140 steel", International Journal of Microestructure and Materials Properties, v. 6, pp. 366-377, 2011.

[15] ASTM - American Society for Testing Materials. "ASTM E 140 - 02 - Standard Hardness Conversion Tables for Metals Relationship Among Brinell Hardness, Vickers Hardness, Rockwell Hardness, Superficial Hardness, Knoop Hardness and Scleroscope Hardness" In: Annual Book of ASTM Standards, pp. 1-21, 2002.

[16] SILVA, S.E.T.P., Análise das propriedades mecânicas e estruturais do aço SAE 4140 submetido a tratamento criogênico, Dissertação de M.Sc., UENF, Campos dos Goytacazes, Rio de Janeiro, RJ, Brasil, 2012. 
[17] RASMA, E.T., Caracterização estrutural e mecânica do aço AISI/SAE 4140 tratado sob diferentes tratamentos térmicos, Dissertação de M.Sc., UENF, Campos dos Goytacazes, Rio de Janeiro, RJ, Brasil, 2015.

[18] ASM INTERNATIONAL, "ASM handbook: metallography and microstructures", 10 ed, Novelty, Russell Township, 1990.

[19] LOUAI, A., POLLET, G., FRANCOIS, J., et al., "Polymer aqueous solutions as quenching media polyvinylpyrrolidone", Journal of Applied Polymer Science, v. 43, pp. 2151-2160, Dec.1991.

[20] TROELL, E., KRISTOFFERSEN, H., "Influence of ageing and contamination of polymer quenchants on cooling characteristics", Berg und Hüttenmännische Monatshefte, v. 155, pp. 114-118, Jun. 2009.

[21] LOMBARDO, S., COSTA, F.H., HASHIMOTO, T.M., et al., "Método para o cálculo da fração volumétrica de austenita retida através do software de análise digital de imagens", In: $19^{\circ}$ Congresso Brasileiro de Engenharia e Ciência dos Materiais, pp. 4968-4975, Campos do Jordão, nov. 2010.

[22] CHEN, C.H., ZHOU, J.E., "The orthogonal-regression analysis on cooling rate of PVP quenchant", Journal of Materials Engineering and Performance, v. 11, pp. 527-529, Mai. 2002.

[23] CULLITY, B.D., "Elements of x-ray diffraction", 2 ed., Phillippines, Addison-Wesley Publishing Company Inc., 1978.

\section{ORCID}

Eduardo da Rosa Vieira

Jorge Luis Braz Medeiros

Luciano Volcanoglo Biehl

Alex Britto da Silva

Marcos Saalfeld da Silva https://orcid.org/0000-0002-6343-3255

https://orcid.org/0000-0003-3468-7632

https://orcid.org/0000-0002-5415-5863

https://orcid.org/0000-0002-0404-9085

https://orcid.org/0000-0002-4330-1327 